\title{
IS GRADUATE SOCIAL WORK EDUCATION PROMOTING A CRITICAL APPROACH TO MENTAL HEALTH PRACTICE?
}

\author{
Jeffrey R. Lacasse \\ Florida State University
}

Tomi Gomory

Florida State University

\begin{abstract}
A sample of 71 psychopathology course syllabi from 58 different graduate schools of social work was analyzed to determine whether different viewpoints and the concomitant empirical evidence were presented regarding 4 significant mental health topics: concepts of mental disorder, reliability and validity of psychiatric diagnoses, biological etiology, and drug treatment. There is little evidence that graduate psychopathology courses cover viewpoints other than the most conventional and institutional — that of biomedical psychiatry. A small handful of secondary (textbooks) rather than primary (research articles) sources provide the majority of the mental health content in these courses. Implications are discussed. The article includes an overview of both the relevant conventional and critical literature.
\end{abstract}

People make too big a deal out of DSM and spend too much time studying it. DSM is a labeling system that is inherently superficial, and it is a convenient fiction to suppose that patients' problems can be broken down into discrete categories. We don't understand the etiology of mental illness, and lab findings are practically never found that are diagnostically useful.

-Michael First, DSM-IV-TR co-chair and editor

No longer do we seek to understand whole persons in their social contexts— rather we are there to realign our patients' neurotransmitters. The problem is that it is very difficult to have a relationship with a neurotransmitter-whatever its configuration.

- Loren Mosher, former chief of the Center for Schizophrenia Studies, National Institute of Mental Health

HiSTORICALLY, the field of social work has been committed to work toward a "just society" (Reamer, 1993). This means that social work has often rejected mainstream institutional views and has offered or supported alternative viewpoints furthering its goal of a just society. In addition, evidence-based practice suggests that professional decision making should rest on the evaluation of well-tested empirical evidence, not prevailing dogma 
(Gambrill, 1999). This commitment to exploring nonmainstream positions is exemplified by the range of arguments found in popular social policy texts authored by social work academics. For example, almost every social policy textbook presents the entire range of arguments for and against the paradigm of welfare reform, epitomized by the Personal Responsibility and Work Opportunity Reconciliation Act of 1996 (e.g., Gilbert \& Terrell, 2002; Karger \& Stoesz, 2002; DiNitto, 2000; Sherraden, 1991). Some authors present detailed alternatives to the conventional wisdom (i.e., Fox Piven, Acker, Hallock \& Morgen, 2002). Typical examples appear in one popular textbook which questions the currently accepted wisdom of for-profit provision of human services: "[d]espite the undesirable attributes of proprietary human service providers, they are likely to continue to play an active role in defining social welfare" (Karger \& Stoesz, 2002, p. 197). This textbook also questions the utility of the entire Temporary Assistance to Needy Families (TANF) program driving much of our current government policy on poverty:

The TANF program is predicated on a kind of welfare behaviorism: an attempt to reprogram the behaviors of the poor. Current welfare reform efforts, however, are unlikely to deliver on the promises of this approach. (p. 291)

Additionally, social work academics have often critiqued the use of interventions that have failed empirical tests, for instance, the use of psychological debriefing (Lewis, 2003). Social work academics have promoted alternatives to the status quo by critically analyzing current policies. For example, in their widely used chemical dependency text, McNeece and DiNitto (1998) find the government's broadly marketed "War on Drugs" deeply flawedafter carefully analyzing this policy and discussing the pros and cons of drug legalization (pp. 192-195).

The present study seeks to assess whether mental health content in social work education is subject to the same critical academic attention as the policy topics just mentioned. Social work has become "the dominant profession staffing mental health services in the United States" (Miller, 2002, p. 66). Are the more than 35,000 MSW students receiving training in a given year (West et al., 2000, p. 293) receiving the best scientific information, evaluation of evidence, and critical analysis currently available on mental health?

\section{Background Literature}

Research on mental health topics relevant to social work education has largely focused on the beliefs of students (Shera \& DelvaTauiliili, 1996), the opinions of practitioners (Kutchins \& Kirk, 1988), or on specific methods for teaching psychopathology (Drolen, 1993). In our review of the literature, we found only one prior article directly bearing on the present study. Raffoul and Holmes (1986) used a national survey of accredited master's programs to examine the integration of Diagnostic and Statistical Manual of Mental Disorders-III (American Psychiatric Association, 1980) content within social work psychopathology courses. Raffoul and Holmes noted an ongoing controversy among academics regarding advantages and disadvantages of using the 
DSM. Their work pointed to the range of "preferred treatment models, philosophies of treatment, and beliefs about psychopathology" (p. 25) held by academics who teach social work students about mental health. This study, completed at the dawn of the modern DSM age, found significant academic support for the inclusion of DSM-related content in social work curricula; of the 57 schools in the sample, 33\% $(n=19)$ had a course "devoted exclusively to DSM-III" (p. 27), and 83\% ( $n=47)$ included some DSM-III content in nondedicated courses. The article also noted some perceived disadvantages of the DSM, such as value conflicts over labeling and a lack of utility for treatment planning (p. 29). We are not aware of any other study assessing psychopathology education in social work since this 1986 Raffoul and Holmes study.

Since then the debate about how best to conceptualize human "mental disorderliness" has continued. The field of social work contains some of the most vocal proponents (Williams \& Spitzer, 1995) of the DSM-organized medical model of psychopathology, as well as some of its most prominent critics (Kutchins \& Kirk, 1995; Wakefield, 1992a). Beyond the issue of the value of the DSM for teaching and clinical practice, there exists an intellectual tension in our field between different models of deviant behavior (Miller, 2002), such as the biomedical (e.g., mental illness as brain disease treated primarily by medication) and the psychosocial (e.g., problematic volitional/influenced behavior amenable to change via talk and behavioral approaches) models. Two quotes from social work academics who have taught psychopathology courses illustrate differing positions in the debate:

\begin{abstract}
Neuroscience has revolutionized our understanding of human behavior. . . mental health and mental illness... during the past two decades. The principle that formerly ran counter to prevailing wisdom has now become axiomatic, that is, that mental illnesses are biological illnesses in the brain. (Johnson, 2002, p. 362)
\end{abstract}

Mental illness involves behavior that is labeled as deviant by someone. If not troubling to the person said to have it, it is troubling to those who are affected by it. The integral relationship between mental illness and deviance explains the changing view of unusual, disliked, or disruptive behavior from sinful, to criminal, to reflective of mental illness. (Gambrill, 1994, p. ix)

In short, academic social work recognizes a variety of explanatory models for disordered behavior ranging from deviance to disease. Proponents of these models all claim the models are "supported" by some "evidence-based" literature (i.e., Cohen, 1989, 1990; Gomory, 1999, 2002; Johnson 1999b; Kirk \& Kutchins, 1992; Kutchins \& Kirk, 1997; Rubin, Cardenas, Warren, Pike, \& Wambach, 1998; Thyer \& Wodarski,1998; Wakefield, 1992b). The present study sought to determine whether the diversity of theory and research found in the mental health literature reached social work students in their psychopathology classes.

\section{Method}

\section{Sampling Frame and Response Rate}

Psychopathology syllabi were solicited during the academic year 2001-2002 from all 
graduate schools of social work listed in the top-80 of the annual U.S. News and World Report rankings (2000). The schools' websites were examined for course listings of psychopathology classes and their instructors. Instructors or administrators or both were emailed an initial psychopathology syllabus request letter. Respondents were offered the option to reply via email or to send a paper copy of the requested syllabus via postal mail. One follow-up email solicitation and a final request for nonresponders through conventional post were made in spring 2002. Additional syllabi were also collected through informal networking methods.

We collected 71 syllabi from 58 different institutions. At least one psychopathology syllabus was received from 58 of the 79 valid institutions (73.4\%), including syllabi from 23 of the top 25 schools ranked.

\section{Procedure}

Each syllabus together with assigned readings were then analyzed for general critical mental health content (i.e., types of texts required, format of syllabus, whether treatments were included or not) as well as for specific content in four important but contentious areas where social work scholars have done significant critical work: (1) concepts of mental disorder, (2) measurement of mental disorder (or reliability and validity of psychiatric diagnosis), (3) biological etiology of mental disorder, and (4) drug treatment of mental disorder. We examined keywords, sentences, paragraphs, and items found in various sections of the syllabi, such as course descriptions, goals and objectives, lecture topics, syllabus organization and structure, and textbooks / read- ings assigned as required readings (on content analysis see, Royse, 1999, pp. 211-221). For the most part we did not analyze recommended readings assuming that optional material was not deemed essential.

We searched for content which presented different positions and well-tested evidence (evidence-based) in each of the four content areas. For instance, in the content area of biological etiology of mental disorder, if information was offered about depression resulting from chemical imbalances in the brain that are corrected by antidepressant medication, then we sought to determine if alternative viewpoints were presented. For example, professor of social work Harriette Johnson states in her text Psyche, Synapse, Substance (1999a) that "The SSRIs [selective serotonin reuptake inhibitors] relieve symptoms of depression. . by remedying the inadequate supply of serotonin that is causing the symptoms" (p.35). Whereas professor of psychology and neuroscience Elliot Valenstein (1998) takes a different position: "Although the often-repeated statement that antidepressants work by correcting the biochemical deficiency that is the cause of depression may be an effective promotional tack, it cannot be justified by the evidence" (p. 110).

\section{Findings}

\section{Sample}

Instructor background. We received syllabi from instructors with an assortment of educational backgrounds, ranging from master'slevel adjunct professors to distinguished full professors. Of the respondents, $1.4 \%(n=1)$ had only a master's degree listed, $15.5 \%(n=11)$ listed themselves as licensed MSW-level practitioners, $46.5 \%(n=33)$ listed a PhD, 15.5\% 
$(n=11)$ listed both a PhD and a social work license, and $21.1 \%(n=15)$ had no degree listed. The majority of the instructors, $61.9 \%(n=44)$, listed a PhD.

Course format. The vast majority of the courses were in the 3-credit-hour format. For $43(74.1 \%)$ of the responding schools we were able to ascertain whether or not they required a psychopathology course in their master's curriculum; $58.1 \%(n=25)$ of these required a course for their clinical students, $13.9 \%(n=6)$ of these schools did not, and 27.9\% $(n=12)$ offered them as "cluster" electives.

Syllabus structure. The majority of the syllabi $(57.7 \%, n=41)$ were titled using the term "psychopathology" or similar expressions such as "psychosocial disorders," followed by "assessment" (12.6\%, n=9), "human behavior" $(7.0 \%, n=5)$, and various other terms used in three or less syllabi $(22.5 \%, n=16)$. Despite these variations, the sample was composed of largely homogenous syllabi stating essentially the same course goals. For instance, "This is a survey course which teaches the student to identify and understand the etiologies and symptomatology of the major groups of emotional and mental disorders as described by the DSM-IV. It highlights the social, cultural, and ethnic factors which impact upon the diagnosis and treatment of these conditions" (quoted from Case 13).

We evaluated how many courses organized their classes along formal DSM disorder categories. If we found more than $50 \%$ of the total available class meetings identified with corresponding DSM headings (such as "DSMIV Introduction," "Psychotic Disorders:Schizophrenia," or "Mood Disorders: Mania, Bipolar Disorder, and Cyclothymia," in Case 4), we judged the syllabus to be organized and structured by the DSM. Using that standard, $88.7 \%$ $(n=63)$ of the syllabi were organized along DSM disorder categories. The remaining $11.3 \%$ $(n=8)$ of the syllabi typically set aside a class or two to cover "DSM-IV: Uses and Critiques" (Case 3), and spent the bulk of the class sessions on various theories of psychopathology and practice methods. Another similarity found among the syllabi was that $76.0 \%(n=54)$ covered some treatment issues in addition to theories, assessment, and classification.

\section{Assigned Readings Within Syllabi}

Required texts. Since $88.7 \%$ of the class syllabi were found to follow the DSM, it was unsurprising to find that the DSM-IV-TR (American Psychiatric Association, 2000) was the most often assigned text, with $74.6 \%(n=53)$ of the syllabi requiring it, including $16.9 \%$ $(n=12)$ of the total sample requiring only the DSM-IV-TR.

The next two most popular texts, both authored by psychiatrists, were Kaplan and Saddock's (1998) Synopsis of Psychiatry (25.4\%, $n=18)$ and Maxmen and Ward's (1995) Essential Psychopathology and Its Treatment (14.1\%, $n=10)$. Kaplan and Saddock is the only text assigned in $8.4 \% \quad(n=6)$ of the syllabi and Maxmen and Ward is the only text assigned in $5.6 \%(n=4)$ of the syllabi. Although several psychopathology texts authored by social workers are listed-Austrian (2000) by 7.0\% $(n=5)$, Turner (1999) by $2.8 \%(n=2)$, and Zide and Gray (2001) by $2.8 \%(n=2)$ of the syllabi, none serve as the stand-alone text for any syllabus. There are 13 different texts authored or edited by social workers in a total of $26.7 \%$ $(n=19)$ syllabi; 11 assigned in one or two syl- 
labi and one (Bentley \& Walsh, 2001), assigned in three. (A list of all required textbooks is available upon request from the authors.)

We found that $28.2 \%(n=20)$ of the syllabi listed a class reader. Only $47.9 \%(n=34)$ require even one article of any sort, and $42.3 \%$ $(n=30)$ had a bibliography attached. Given the extremely dynamic nature of mental health research and education (and related topics such as psychotropic drug effects), it is a striking finding that over half of the students in our sample leave their psychopathology course without being required to read a single journal article.

Social work mental health literature content. Nearly half the syllabi $(45.0 \%, n=32)$ do not require any readings (including texts) by a social work author, and 33.8\% $(n=24)$ neither require nor recommend any readings by any social work authors. This may be due to the interdisciplinary nature of psychopathology research, a reliance on psychiatric sources, limited acquaintance with the empirical literature, or all three.

\section{Issue 1: Conceptualizations of Mental Disorder}

Various models for explaining "mental disorderliness" that may be important to social work's practice and policy approaches fall on a continuum. At one end lies the "rhetorical" model of deviant or disvalued behavior (Vatz \& Weinberg, 1994). This model views the behaviors (including language use) labeled by the DSM "symptomatology," as socially and politically disvalued, volitional, goal-oriented, meaningful conduct open to potential change ideally through voluntary effort of client and worker. The model is represented by psychia- trist Thomas Szasz's conceptualization of troubling or troubled behavior as "problems in living" (Szasz, 1987, 2001; for a critique see Schoenfeld, 1976). On the other end of the continuum, representing a medical "disorder" perspective on problematic behaviors as "determined motion" or symptoms, lies social work academic Jerome Wakefield's view of mental disorder as "harmful dysfunction," consisting of the failure of a mental mechanism to function as "designed" plus a societal judgment that the failure led to harm (Wakefield, 1992b; for a critique see Boyle, 2002, pp. 224-231). Although Szasz's and Wakefield's models hold opposing views about the conceptual validity of the domain of psychopathology, they are both, in different ways, very critical of the DSM nosology and mental disorder definition.

Other models exist along this continuum. Closer to Szasz's approach but omitting definitive judgments on etiology lies sociologist Thomas Scheff's (1999) labeling theory, a sociological perspective which views mental illness as a residual category of deviance made up of individuals' reactions to norms and attitudes held by others toward those with psychiatric diagnoses. Discontinuity theory developed by the current president of the American Psychological Association, Philip Zimbardo (1999), is another. This theory argues that societally disapproved explanations propounded by ordinary people through universal behavioral search processes in attempts to understand and explain personally painful experiences (called discontinuities), which are rigidly defended by the person despite such disapproval, over time lead to mental illness. We were interested in seeing if these, or other 
well-argued and more familiar alternatives along the continuum (i.e., psychodynamic, interpersonal, cognitive-behavioral, family systems, etc.), were offered for review.

How mental disorder is portrayed in the syllabi and assigned literature. Many of the syllabi $(42.3 \%, n=30)$ assert an intention to address a range of views about "what is mental disorder" either by explicitly stating this or making reference to terms such as "deviance" or "psychosocial dysfunction." We examined the course description and objectives for the use of the words "political" (which we saw as congruent with Szasz's views), or "sociological" (which we saw as reflective of Scheff's viewpoint), or some variation of the two terms in relation to causes and conceptualizations of "mental disorderliness;" 23.9\% $(n=17)$ included the term "sociological" and 18.3\% $(n=13)$ used the term "political." To review the actual course content on alternate mental disorder perspectives (as differentiated from statements about the intention to address the issue) we reviewed all assigned readings. We found that 5.6\% $(n=4)$ of syllabi required a reading by Szasz and $2.8 \%(n=2)$ contained his work in either their recommended list or bibliography. Neither Scheff's nor Wakefield's work was required in any of the syllabi we examined; one syllabus $(1.4 \%)$ required an article by Levy (1981), which incorporated labeling theory. Wakefield's work on harmful dysfunction was found in two bibliography entries $(2.8 \%)$. Two $(2.8 \%)$ syllabi contained an article by Widiger and Sankis (2000), which offered valuable in-depth content on the concept of mental disorder.

The DSM and various psychiatric textbooks are the only assigned texts in $63.4 \%$ $(n=45)$ of the syllabi and use the DSM definition of mental disorder (e.g. Maxmen \& Ward, 1995, p. 5). The abnormal psychology texts used in some courses are more comprehensive, but all of them together are only assigned in $8.4 \%(n=6)$ of course syllabi.

Although the ideas of Thomas Szasz are detailed in an academic career spanning hundreds of journal articles, over 25 books, and 50 years and have been cited widely in the health, legal, ethics, and social science literature, Szasz is generally dismissed in psychiatric texts. In the second most-used text after the DSM in our sample of syllabi, Maxmen and Ward (1995) make only this mistaken statement about Szasz's perspective:

Critics like Thomas Szasz argue that because the line between psychopathology and normality is hazy, psychopathology is a myth. That's nonsense. Day and night exist, even though at dusk it is hard to know which it is. Psychopathology is no less real for its relativity. (p. 5; for a more accurate description of Szasz's position, see Vatz \& Weinberg, 1983)

Some other perspectives or practice models were contained within some of the courses we examined. We assumed content merely if the name of a perspective or model was listed anywhere in the syllabus. We found that $39.4 \%$ $(n=28)$ of the courses named at least one alternative perspective. Psychodynamic was by far the most prevalent ( $n=22,31.0 \%$ ), followed by ecosystems / family systems $(n=9,12.7 \%)$, cognitive/cognitive-behavioral ( $n=7,9.9 \%)$, feminist $(n=5,7.0 \%)$, and behavioral $(n=3,4.2 \%)$. Existential, social learning, and narrative 
perspectives were listed in two or fewer syllabi, accounting for no more than $2.8 \%$ of the total each.

\section{Issue 2: Reliability and Validity of the DSM}

For science to grow it is essential that the problems we wish to tackle be real. That is, in order to make progress toward problem resolution in the real world, we need to be sure that a concept or entity related to a problem exists and that we can consistently agree on how to identify it. For example, if we wish to explain an occurrence of violent and threatening behavior for which the perpetrator offers an explanation "that the devil commanded me to do it," by calling the occurrence the result of the DSM-defined mental disorder schizophrenia, then we would want to make sure that this disorder actually exists (Boyle, 2002). This entails the interrelated problems of the reliability and validity of putative scientific entities, in this case of a DSM mental disorder. Social work academics Stuart Kirk and Herb Kutchins strongly critique the reliability of DSM mental disorders. They have found the claims for diagnostic reliability of the DSM to be significantly flawed in all three of the modern versions (DSM-III, $-I I I-R$, and $-I V)$, each of which were specifically designed to address the problems of reliability found in earlier versions (Kirk \& Hsieh, in press; Kirk \& Kutchins, 1992, 1994; Kutchins \& Kirk, 1997).

Kirk and Kutchins have focused their research on the issue of reliability not only because that is what psychiatrists have addressed, but also because "a classification system that is unreliable. . . cannot be valid" (Kirk \& Kutchins, 1992, p. 32). Of course, a reliable concept can be completely invalid. Most people agree about what a "sunrise" looks like. Such judgments are reliable (i.e., consistent across observers), but such judgments are wrong, the observations are invalid and in error. The sun does not rise; the earth rotates on its axis and orbits around the sun, creating the optical illusion of the sun's rise. Even Nancy Andreasen, chair of the DSM-IV Schizophrenia Work Group and a leading researcher and proponent of biological explanations for schizophrenia, agrees with Kirk and Kutchins's criticisms. She states in her coauthored psychiatric textbook (Andreasen \& Black, 2001) that

The DSM criteria are simple provisional agreements, by a group of experts, on what characteristic features must be present to make a diagnosis. Although the criteria are based on data whenever possible, the available data are often inadequate for building the criteria. Thus, the selection of signs and symptoms is often relatively arbitrary. The diagnoses themselves are certainly arbitrary. They will remain arbitrary as long as we are ignorant about pathophysiology and etiology. Biologically oriented psychiatrists have objected to the lack of validity in the $D S M$ as well. In this instance, they point to the arbitrary nature of the definitions, which are not rooted in information about biological causes. (pp. 35-36)

Another social work academic engaged critically with issues of mental health and treatment, David Cohen, together with his coauthor argues in a recent article that the DSM is internally inconsistent and cannot be scientifically 
justified according to the standards articulated by the medical paradigm adopted by contemporary psychiatry itself (Jacobs \& Cohen, in press).

How reliability and validity are discussed in class syllabi and assigned literature. We searched each syllabus (including course assignments) for the words "reliability" and "validity." Nearly $13 \%(12.7 \%, n=9)$ of the syllabi contained the word "reliability" by stating, for example, that one course objective was to "understand problems of reliability of mental health labeling systems" (Case 11). Almost 6\% $(5.6 \%, n=4)$ of the syllabi contained the word "validity." Overall, 87.3\% $(n=62)$ of the syllabi we examined did not contain these words, which we saw as possible indicators of a critical or scientific outlook on DSM. However, content on reliability/validity, even not explicitly named, might still be found under other syllabus subheadings, such as "Controversies around $D S M^{\prime \prime}$, or in the course readings. To that end, we performed a more detailed analysis on how required readings might have addressed the issues of reliability/validity.

Reliability and validity content of assigned material. We reviewed assigned textbooks and procured all journal articles that were assigned reading when diagnosis was addressed in the syllabi. Of the 71 syllabi collected, we were able to examine all the relevant readings for $95.8 \%(n=68)$.

Of the syllabi we examined for this analysis, $15.5 \%(n=11)$ used the DSM as the sole required text. The DSM itself does not contain any substantive information about reliability or validity; in fact, the words "reliability" and "validity" do not appear in the index. Readers who are interested in these issues are referred to the fourth volume of the DSM-IV Sourcebook series (American Psychiatric Association, 1998), which contains the data reanalyses and field trials relating to the diagnostic categories. The fourth volume published in 1998 is currently out of print and has been for several years, complicating scholarly analysis of the improved reliability of DSM mental disorders claimed by its proponents.

Nearly $30 \%(28.1 \%, n=20)$ of the syllabi assigned a psychiatric textbook containing no empirical content on the problems of DSM reliability and validity. Also, these syllabi did not assign any articles with such content. Ten syllabi (14.1\%) required no relevant articles but required textbooks that had some content on reliability and validity; these ranged from a short acknowledgment of the extant critiques (Zide \& Gray, 2001) to briefly summarizing the empirical literature(Brubeck, 1999). About30\% $(29.6 \%, n=21)$ of the syllabi required at least one reading which offered some critical discussion relevant to the practice of psychiatric diagnosis; the most frequently assigned article was the Journal of Social Work Education's Point/ Counterpoint debate, "Should DSM Be the Basis for Teaching Social Work Practice in Mental Health?" between Kutchins and Kirk (1995) and Williams and Spitzer (1995), required in nine syllabi (12.7\%). Other articles assigned include a general critique of the DSM (Wylie, 1995; 8.5\%, $n=6$ ) as well as classic critiques, such as Rosenhan's (1973) “On Being Sane in Insane Places" $(4.2 \%, n=3)$. While some of these articles offer compelling information regarding some problems with psychiatric diagnosis, none offer empirical data-driven critiques of reliability and validity. Only $8.5 \%$ $(n=6)$ of class syllabi required even one publi- 
cation empirically critiquing the reliability of the DSM (i.e., Kirk \& Kutchins, 1992, 1994;

Kutchins \& Kirk, 1997).

Some assigned readings overstated the reliability and validity of the DSM. For instance, Hales and Hales (1995) state, "Because of its widespread use, clinicians today agree on diagnoses approximately eighty percent of the time, far more frequently than in the past" (p. 8). No citation for this claim is provided in the text. Andreasen and Black (2001) also assert without providing a citation that "the kappa statistics for most diagnoses are approximately 0.8 or greater, which is considered very good" (p. 34). Another assigned text referenced Kirk and Kutchins for the claim that "On average, experienced clinicians only agreed on their diagnoses using these manuals about 70 percent of the time" (NolenHoeksema, 1998, p. 52). Our review failed to find such a claim in any of Kirk and Kutchin's works and when we contacted the author of the text, the author was unable to indicate where in the referenced work she found the 70\% agreement figure (Nolen-Hoeksema, 2002, personal communication, December 11, 2002).

Kirk and Kutchin's (1992, 1994) work suggests that the average kappa means are closer to .60 across reliability studies of DSM-III and $-I I I-R$ diagnoses on patient samples and far worse, .37 on non-patient samples (1994, p. 81, figure 2 and p. 82, figure 3). The authors conclude:

The findings of this elaborate reliability study were disappointing even to the investigators. The kappa values are not that different than those from the preDSM-III studies and in some cases ap-

\begin{abstract}
pear worse.... Despite the scientific claims of great success, reliability appears to have improved very little in three decades. (p. 83)
\end{abstract}

Kirk and Hsieh (in press) have more recently examined the percent agreement among experienced clinicians (social workers, clinical psychologists, and psychiatrists) diagnosing conduct disorder according to DSM-IV criteria. Their research found "substantial disparity in the DSM diagnoses used by experienced clinicians. [S]electing either the same or a different diagnosis, the nearly 50/50 split demonstrates no more than a chance agreement, the mere flipping of a coin" (p. 16). The difficulties of the reliability of DSM disorders appear to continue in the latest version of the "psychiatric Bible."

\section{Issue 3: Biological Etiology}

Regarding the etiology and treatment of mental disorder, there are two distinct points of view. First, there is the hypothesis that certain collections of problematic behaviors psychiatrically labeled "mental disorders" are caused by malfunctioning brain neurochemistry, a position held by the National Institute of Mental Health (2000):

Since... 50 years ago, much has been learned about mental disorders and their effects on the brain. Revolutionary scientific advances in neuroscience, molecular biology, genetics, and brain imaging have provided some of the greatest insights into the complex organ that is the seat of thought, memory, and emotion. Thanks to these new tools, the scientific evidence 
that mental illnesses are brain disorders now exists. (p. 1)

The advocacy organization for families of clients who are diagnosed as mentally ill, the National Alliance for the Mentally Ill (n.d.), agrees:

During the last decade... scientific research has greatly expanded our understanding and firmly established that mental illnesses like major depression are biologically-based brain diseases. (p. 1)

Some social work academics agree with this view reductively attributing the cause of many mental disorders (complex global behavioral phenomena) to misfiring neurotransmitters, such as dopamine and serotonin. For instance, social work professor Harriette Johnson's (1999a) text, Psyche, Synapse, and Substance, is devoted to explaining the neurobiology of addiction and mental disorder. Psychiatric texts such as Kaplan and Saddock (1998) contain detailed discussions about the various neurotransmitter systems, the mental disorders they are said to be correlated with, and the medications that act upon these neurotransmitters in the brain.

However, significant critiques of the disease model exist (in social work see Cohen, 1989, 1990; Gomory, 1998; Tyson, 1991). An article (Knutson et al., 1998) reporting on SSRI effects on normal populations in a recent double-blind randomized controlled trial contradicts the claimed disease-specific effects by such drugs, undermining the global claim that SSRIs are ameliorating a putative biochemical imbalance found only in the mentally ill:
This is the first empirical demonstration that chronic administration of a selective serotonin reuptake blockade can have significant personality and behavioral effects in normal humans in the absence of baseline depression or other psychopathology. (p. 378)

A recent discussion with psychiatrist David Burns, well known both for his work on cognitive-behavioral therapy and as a winner of the prestigious A. E. Bennett Award (granted by the Society for Biological Psychiatry for his research on serotonin) yielded the following:

I spent the first several years of my career doing full-time research on brain serotonin metabolism, but I never saw any convincing evidence that any psychiatric disorder, including depression, results from a deficiency of brain serotonin. In fact, we cannot measure brain serotonin levels in living human beings so there is no way to test this theory. Someneuroscientists would question whether the theory is even viable, since the brain does not function in this way, as a hydraulic system. By way of an analogy, if you had a problem with your computer, it would probably result from a software glitch, and not from a silicon deficiency in one of the chips. Physicians who tell their patients that their depression and anxiety result from a chemical imbalance in the brain are confusing theories with facts. Of course, the drug companies encourage this type of message, because it stimulates enormous sales for the popular and costly SSRI antidepressants. (Burns, personal communication, April 29, 2003) 
The surgeon general's recent mental health report(U.S. Department of Health and Human Services, 1999) also confirms the conjectural nature of claims about the biological basis of mental disorderliness:

[T] here is no definitive lesion, laboratory test, or abnormality in brain tissue that can identify [mental] illness.... All too frequently, a biological change in the brain (a lesion) is purported to be the "cause" of a mental disorder. The fact is that any simple association-or correlation-cannot and does not. . mean causation. (pp. 44-51)

How biological etiology is portrayed in syllabi and assigned literature. Slightly more than $25.3 \%$ $(n=18)$ of the syllabi included course goals or descriptions representative of chemical imbalance theory. For instance, the course description for Case 1 reads, "individuals who are licensed. . . should demonstrate that they recognize the differences between biologicallybased brain diseases." Other syllabi used terms like "neurochemistry" (Cases 18 and 47), "neurochemical substrates" (Cases 36 and 55), and "neurobiological" (Case 58) to describe potential causes of mental disorder. An additional $43.6 \%(n=31)$ of assigned textbooks contain bioreductionistic content, such as "norepinephrine and serotonin are tied to depression.... Depression occurs when the regulatory function of the neuroreceptors breaks down" (Austrian, 2000, p. 47). Two courses assigned an article by Taylor (1987) entitled "Biological Basis of Schizophrenia." All told it appears that at least $71.8 \%(n=51)$ of the courses included some content on chemical imbalance theory.
We next examined the syllabi to see if published academic critiques of these biological theories were offered anywhere in the syllabi including required readings, recommended readings, and bibliographies. We were looking for any classic critiques of biological psychiatry (Breggin, 1991; Fancher, 1995; Ross \& Pam, 1995) as well as literature on specific disorders/treatments (Valenstein, 1998; Glenmullen, 2000), critical responses to articles positing a disease model view (i.e., Cohen, 1989), or empirical articles from the field of biological psychiatry which found, for instance, that brain changes in those diagnosed with schizophrenia may be attributed to psychotropic medication rather than to schizophrenia-related neuropathology (Corson, Nopoulos, Miller, Arndt \& Andreasen, 1999). We located five syllabi containing such readings $(7.0 \%$ of the sample); of those, three placed these critiques in recommended readings, and only two listed such readings as required. Critiques of biological reductionism were found in very few of the course syllabi in our sample.

Some required texts contained potentially misleading content. For example, Johnson (1999b) contains photographs of positron emission tomography (PET) scans from Zametkin et al. (1990) comparing an "ADHD" brain with a "normal" brain, which appear dramatically different in the illustration. Johnson reports that a malfunction in cerebral glucose metabolism results in "impulsive behavior arising from deficits in inhibition" (Johnson, 1999b, p. 59, emphasis in original). Hales and Hales (1995, p. 338) report similarly. To students unaware of the critical literature against which to evaluate 
such brain imaging photographs and authority-based assertions, it certainly might appear that the controversy regarding the psychiatric diagnosis of ADHD has been resolved; that it is a valid disease entity for which diseasespecific neuropathology has been located.

However, Alan Zametkin himself reported in 1991 (cited in Breggin, 1998):

\begin{abstract}
One commonly asked question of our brain imaging studies is whether or not PET scanning can be used to diagnose ADHD. Unfortunately, this is not currently possible because there is considerable overlap in our study between normal and ADHD brain metabolism. (p. 169)
\end{abstract}

The brain-imaging studies relevant to ADHD have been rife with confounds and have not resulted in any significant neurobiological findings, despite widespread reports to the contrary (Breggin, 1998; Leo \& Cohen, 2003). Less than 1 year after Alan Zametkin's much heralded 1990 study was published, social work professor Katherine Tyson (1991) published this in response:

The abnormal distribution pattern of cerebral glucose metabolism in the experimental sample. . is not associated with variations in the behavioral variable of attention. . the authors found that even when the control group and experimental group differed in cerebral glucose metabolism in some areas of the brain, these groups had no functional differences on the measure of attention. (p. 140, emphasis in the original)
Zametkin and colleagues' (1993) later study found that "as assessed by PET scanning, global cerebral glucose metabolism in hyperactive teens was not significantly different from that of the control group" (p. 336). The National Institutes of Health (1998) Consensus Statement on ADHD states, "an independent diagnostic test for ADHD does not exist."

\section{Issue 4: Psychotropic Medications}

The debate about the utility, safety, and efficacy of psychiatric medications is contentious. From the mental-disorder-as-brain-disease perspective, medications are thought to be invaluable in the treatment of mental disorders. For instance, in Hales and Hales (1995), “New psychiatric medications are correcting chemical imbalances in the brain with far fewer side effects than older drugs" (p.8). Psychotropic medications are a growth industry-even for children. The use of antidepressant medications for that group has more than doubled in 10 years (Goode, 2002). Antidepressants are generally viewed as safe and effective treatments for depression and are routinely prescribed by general practitioners and psychiatrists: "the effectiveness of antidepressants is unquestioned" (Andreasen \& Black, 2001 , p. 720). They are said to be $60-70 \%$ effective in the treatment of depression (Bentley \& Walsh, 2001). At least five social workers have published texts disseminating information on psychiatric medications, generally echoing these claims (Austrian, 2000; Bentley \& Walsh, 2001; Dziegielewski, 2001; Turner, 1999).

The critical literature disagrees. For example, some of the empirical literature on 
SSRIs, one of the latest group of antidepressants which are asserted to have fewer adverse effects than earlier antidepressants, has noted significant problems associated with their use and claimed antidepressant-specific effects. Psychiatrist Colin Ross has argued that psychiatric medications are not based on ameliorating neurochemical lesions found through neuroscience research, but are created through a speculative process called "chemical roulette" and then marketed on the basis of whatever the current "hot" neurotransmitter is (Ross \& Pam, 1995, pp. 110-111, 117-118). Healy (2000, 2001) found that SSRIs can induce suicidality and concludes elsewhere that the competing agendas and interests of the various participants in the political economy of psychiatric research can result in bad science (Healy, 2002). Social work professor David Cohen is coauthor of a book (Breggin \& Cohen, 1999) which guides clients through the difficult withdrawal process when discontinuing psychiatric medications (including SSRIs). This problem has received public attention recently when the FDA temporarily prohibited the use of ads for Paxil which claimed that the antidepressant was not habit-forming (Peterson, 2002; White, 2002). Cohen $(1988,2002)$ has also been active in calling for the field of social work to consider the use of psychiatric drugs within the broader context of the political economy of psychiatry, especially the pharmaceutical industry's role and impact. He also has called for a closer scrutiny of the clinical trials used to assert the efficacy of certain psychotropic drugs as "proven" or "evidence-based."

Antonuccio, Burns, Danton, and O'Donahue (2000) reviewed the evidence for antidepressant efficacy and concluded that
SSRIs are only marginally more effective than inactive placebos and no more effective than active placebos. A very recent study (Kirsch, Moore, Scoboria, \& Nicholls, 2002) reviewed all the drug efficacy data contained in doubleblind randomized trials submitted by pharmaceutical companies to the U.S. Food and Drug Administration for the six most widely prescribed antidepressants approved between 1987 and 1999 (Prozac, Paxil, Zoloft, Effexor, Serzone, and Celexa). They found the mean difference between the active drug and placebo to be a 2-point difference favoring the drug on the Hamilton Depression Scale. This 2-point differential on the scale translates to no clinical difference. Finally, Joseph Glenmullen (2000) has publicized research indicating that SSRIs can cause harmful neurological effects such as tardive dyskinesia and drug-induced Parkinsonism, and cites studies indicating that SSRI-induced sexual dysfunction occurs in 58 $86 \%$ of patients studied (pp. 29-63, pp. 106-134). How the issue of psychotropic medication is portrayed in syllabiand assigned literature. Slightly less than $50 \%(47.9 \%, n=34)$ of the syllabi contained statements directly indicating that learning about medications was part of the course content. Medication content was identified by phrases such as "understanding the role of psychotropic medication" (Case 7), "uses of most commonly used psychotropic medications" (Case 13), or "benefits and problems associated with pharmacological interventions" (Case 24). An additional 29.6\% $(n=21)$ syllabi did not mention medications within the text of the syllabus but required a textbook with psychotropic medication content (such as Austrian, 2000; Bentley \& Walsh, 2001; Kaplan \& Saddock, 1998; Maxmen \& Ward, 1995). We 
assessed the level of critical content on psychotropic medications by examining each syllabus, the required and recommended readings, as well as all the bibliographies, some in excess of 10 pages. We looked for readings by such authors as David Cohen (1988, 1989, 1997, 2002), David Healy (1997, 2000, 2001, 2002), Joseph Glenmullen (2000), David Jacobs (1995, 1999), Peter Breggin (1991, 1997, 1998), Elliot Valenstein (1998), Seymour Fisher and Roger Greenberg (1989, 1997), David Antonuccio (1995), Irving Kirsch and Guy Sapirstein (1998), Sidney Gelman (1999), Lucy Johnstone (2000), Richard DeGrandpre (1999), and also looked for coauthored projects by the above listed authors (i.e., Cohen \& Jacobs, 2000; Antonuccio et al., 2000). After analyzing all the syllabi, only $4.2 \% \quad(n=3)$ of the syllabi contained a critical reading. Two of these syllabi listed Valenstein (1998) only, a third listed Gelman (1999); and required the article by Corson et al. (1999) briefly discussed earlier in the biological etiology section. Disturbingly, this latter study was the single required critical article on negative effects of medication in the entire sample and was required in just one syllabus.

\section{Discussion}

\section{Limitations}

The representativeness of this study is limited by its cross-sectional nature and also by the variable character of academic courses in general (e.g., if another instructor takes over the course, the content may change). While we believe that most social work academics would agree that the schools in the study are representative of quality schools of social work and adequately serve the intended purpose of identifying a reasonable study sample, only 79 of the 153 Council on Social Work Education accredited master's programs were surveyed. We are unaware of any systematic factors that would lead non-top-80 schools to present more critical mental health content than those in our sample, but we cannot exclude this possibility. In our preliminary research we received a psychopathology syllabus from a university outside of our sampling frame that contained substantial critical content; there may be others. Further, content analysis in part requires interpretation, and although we tried to minimize this by self-critical methodological rigor (Gomory,2001,pp. 28-34), subjective bias may have distorted the study's findings.

One additional limitation was that, for some syllabi, it was difficult to determine which readings were required, suggested, or recommended.Some listed many readings and noted that the instructor would require a portion of them; others gave students the option to pick from a list. When it was unclear, we decided to code the readings as "required." Our results therefore tend to overestimate the degree to which alternative or critical viewpoints are presented in these course syllabi.

Overall, the courses we examined do an excellent job of presenting the psychiatric information regarding the diagnosing and treatment methods of mental disorders as represented by the American Psychiatric Association's DSM medical model. However, put in the most positive light, very few of the alternate explanatory theories and latest scientific research critical of the mainstream psychiatric approaches on questions of reliability and validity of mental disorders, their putative biological etiology, or claims of effective treatment via psychiatric drugs appear to be 
well-represented in these classes (see Table 1). It is our anecdotal experience that many students enter our (the authors') psychopathology classes with some awareness of the biological theories about mental disordersmany believe they are factual. Some mention that they have been exposed to them through articles in the general print media or through drug company advertisements. Cohen (2002) notes, "the idea that the distress and disorders we refer to as mental illness are genuine physical diseases completely pervades our culture" (p. 230). Given that many social work students are "prepped" by conventional wisdom about these issues before they attend classes, and the role of higher education is, in part, to replace simple "commonsense" belief by empirical knowledge, why do social work academics teaching psychopathology courses not routinely offer the full range of available critical material, much as some of our social work colleagues appear to do in the field of social welfare, as we argued at the outset? We conjecture below some possible answers for future discussion.

\section{Subservience to Psychiatry}

Social work's lack of critical content in mental health has much to do with the profession's inability to set itself apart ideologically from psychiatry. From its origin, social work relied on identifying pathology and diagnosing, very much like psychiatry (i.e., Kirk, Siporin, \& Kutchins, 1989; Lubove, 1983; Margolin, 1997). The profession of social work developed partly from the medical model's startling 19th-century reconstruction of what

TABLE 1. Percent of Syllabi Reviewed That Met Specific Criteria $(N=71)$

\begin{tabular}{|c|c|c|}
\hline Criteria & $\%$ & $n$ \\
\hline Were organized by DSM categories & 88.7 & 63 \\
\hline Covered treatment issues & 76.0 & 54 \\
\hline Did not require students to read a single journal article & 52.1 & 37 \\
\hline Listed the $D S M-I V-T R$ as the only required reading & 15.5 & 11 \\
\hline Used some variation of the term "sociological" when describing mental disorders & 23.9 & 17 \\
\hline Used some variation of the term "political" when describing mental disorders & 18.3 & 13 \\
\hline Listed at least one alternative conceptualization of mental disorder and treatment & 39.4 & 28 \\
\hline Required a reading by Thomas Szasz (prominent critic of institutional psychiatry) & 5.6 & 4 \\
\hline Required a reading by Jerome Wakefield (mental disorder as “Harmful Dysfunction") & 0.0 & 0 \\
\hline Used the term "reliability" an indicator of critical outlook on DSM & 12.7 & 9 \\
\hline Used the term "validity" an indicator of critical outlook on DSM & 5.6 & 4 \\
\hline Required a reading which critiqued psychiatric diagnosis & 29.6 & 21 \\
\hline Required a reading which empirically critiqued reliability and validity of $D S M$ & 8.5 & 6 \\
\hline Addressed biological etiology either directly or in assigned readings & 71.8 & 51 \\
\hline Required a reading which critiqued biological etiology & 1.4 & 1 \\
\hline Recommended or listed in bibliography a reading which critiqued biological etiology & 5.6 & 4 \\
\hline Addressed psychiatric medications either directly or in assigned readings & 77.5 & 55 \\
\hline Required a reading which critiqued the use of psychiatric medications & 1.4 & 1 \\
\hline $\begin{array}{l}\text { Recommended or listed in the bibliography a reading which critiqued the use } \\
\text { of psychiatric medications }\end{array}$ & 4.2 & 3 \\
\hline
\end{tabular}


Andrew Abbot (1988, pp. 280-314) calls "the Personal Problems Jurisdiction." Social work and various other helping professions claimed expertise and competed for hegemony over this ill-defined-but immensely vast-set of problems. Psychiatry eventually prevailed in this contest by asserting itself as both reputable medicine and good science. Social work wound up as psychiatry's "handmaiden" due to its highly diffuse and nontechnological nature lacking domain-specific theories, its relative disinterest in scientifically testing its claimed expertise, and the fact that the vast majority of its practitioners were women competing for professional turf in an era of total male domination (Abbot, 1988). In order to survive as a "player" in the personal problems jurisdiction in the new scientific age, social work had to look "scientific" and in this domain the only "science" in town was psychiatric.

Dorothea Dix, one of social work's avatars (Trattner, 1979, p. 55, calls her a "great figure"), illustrates both the strong historical ties between psychiatry and social work and the shortcomings of this relationship. Active in the mid-1800s, she wanted to help a group of deeply troubled individuals ("the insane") treated miserably by the prevailing penal authorities. She argued that insanity was a medical disease and its sufferers needed treatment. Her solution was to "convince the legislators to fund public insane asylums. She claimed. . . that insanity was curable and. . only the lack of funding. . . was holding up the elimination of this grave. . problem" (Leiby, 1978, p. 67). However, her method of gathering popular support for mental health services probably set a precedent that today still haunts the profession of social work.
To argue her cause, Dix relied on false statistics and false claims about the curative powers of treatment. As the historian of mental health, Gerald Grob (1994) notes, "She was not above employing exaggerated rhetoric or embellishing facts. ... She was often mistaken, and this has thrown doubt over all her statements" (p. 47). She apparently made little effort to "accurately" report or question the validity of the data she used because they supported her a priori assumptions about insanity being a medical disease. Historian Andrew Scull (1981) reports that Dix, "Repeatedly. . . informed state legislatures that 'all experience shows that insanity reasonably treated is as certainly curable as a cold or a fever'. She drew upon the elaborate statistics provided by. .. the asylum superintendents" (p. 156). David Rothman (1990), the medical historian further tells us that,

The. . . [superintendents] aggressively asserted that properly organized institutions could cure almost every incidence of the disease.... These statistics were inaccurate and unreliable. Not only was there no attempt to devise criteria for measuring recovery other than release from an institution but in some instances a single patient, several times admitted, discharged and readmitted entered the list as five times cured.... Dorothea Dix['s]. . formula was simple and she repeated it everywhere: first assert the curability of insanity, link it directly to proper institutional care and then quote prevailing medical opinion on rates of recoveries. (pp. 131-132) 
The syllabi we reviewed suggest that, like Dix, social workers are very interested in helping those labeled as mentally ill and still prefer to continue our historical attachment to the male-dominated profession of psychiatry and its medical model. We do not appear to have the professional self-confidence to forge our own separate perspective, even based on the existent well-tested science that often contradicts much that is asserted to be factual by institutional psychiatry.

\section{DSM's Utility as a Reimbursement Tool}

For professional economic survival it is imperative that a clear payment mechanism be in place for service reimbursement. The DSM classification system of coded mental disorders provides the reimbursement mechanism for mental health services along the lines developed for medical reimbursement for physical illnesses from private insurance, Medicaid, SupplementalSecurity Income, and other government programs. A systematic randomized national survey found that clinical social workers overwhelmingly used it for business purposes and not for its clinical validity (Kutchins \& Kirk, 1988). Professional necessity strongly influences the focus on the DSM in mental health classes.

\section{Reliance on Secondary Sources for Information}

The reliance of psychopathology courses on secondary (text books) rather than primary sources (theoretical and empirical research articles) to inform mental health course content we believe reduces critical thinking opportunities while promoting error. Our findings that less than half ( $n=34,47.9 \%$ ) of the course syllabi require even one article of any sort illuminates a serious problem. We found in our analyses of some of the secondary sources, that these are highly fallible interpreters of the primary research material. Two textbooks written by psychiatrists, without offering any references, assert that reliability of psychiatric diagnoses are improving and now are at a very respectable average kappa value of .8 (Andreasen \& Black, 2001; Hales \& Hales, 1995). Another textbook (Nolen-Hoeksema, 1998), citing a primary source, indicates a kappa value of .7, rather than the average kappa value of .6 in one sample and of . 37 in the other, found in the empirical work of the cited researchers (see present article p. 392). If syllabi had assigned the original empirical analysis, a comparison would have quickly identified the error. But since over $91 \%$ of the syllabi failed to assign any empirical articles on reliability by Kirk and Kutchins, the leading researchers evaluating DSM reliability, the false "fact" of increased DSM reliability was maintained. Gomory (2001) has discussed the serious limitations of uncritical secondary source utilization by social work academics, and Joseph (2000) has analyzed the content bias and inaccuracy found in textbooks reporting on psychiatric research. We recommend the routine inclusion of primary empirical sources, both those "supporting" as well as those critiquing essential content areas, along with survey texts, in order to promote evidence-based practice and critical debate about complex behavioral issues.

\section{Mental Disorder Promoted as Brain Disorder}

The National Institute of Mental Health's (1999) decision to view "mental disorder" as 
brain disorder promotes a national biological research agenda:

The mission of the National Institute of Mental Health (NIMH) is to diminish the burden of mental illness.... Through research in basic neuroscience, behavioral science, and genetics we can gain an understanding of the fundamental mechanisms of what goes wrong in the brain in mental illness. (website welcome page)

This institutional emphasis on biological explanations for mental disorders by the federal government entity chiefly responsible for funding research on mental health in the United States strongly influences the nature of the research pursued by the academic institutions attempting to access the nearly 1 billion NIMH dollars available. The assumption of biological causality nicely meshes with the $D S M^{\prime}$ 's medical view (AmericanPsychiatric Association, 2000, pp.xxxxxxi). The critical empirical literature we have identified questions theapparently unquestioned assumption that, "mental illnesses are real diseases of an organ-in this case, the brain" (Hyman, 1998).

But, since the key federal funding source (NIMH) limits research content to that which adheres to the DSM medical disorder paradigm, little incentive exists for academics attempting to survive in a publish/research or perish environment to subscribe to alternative intellectual positions while attempting to fashion an academic career (Duesberg, 1996, pp. 65-67). Schools of social work in their psychopathology classes may simply be reflecting the current academic deference to the intellectual framework of the primary funding source. They demonstrate an understandable professional confirmatory bias (Nickerson, 1998) toward providing students information necessary for professional legitimation and a similarly understandable reluctance to acknowledge conflicting information undermining that effort.

\section{Conclusion}

Finally, in thinking about the apparent one-sided approach to mental health education in social work master's-level psychopathology classes found in this study, social work educators might want to take cognizance of some of the findings in the latest federal report issued by the Center for Mental Health Services of the Substance Abuse and Mental Health Services Administration on the state of mental health knowledge at the millennium. It offers a refreshing, skeptical take which social work educators might integrate into their graduate mental health course curricula. In a chapter authored by David Mechanic (2000), the director of the NIMH Center for Research on the Organization and Financing of Care for the Severely Mentally Ill, we find the following on:

\section{Brain research}

New imaging technologies have made it possible to directly track changes in the brain. . . to potentially use. . . for specific targeting of drugs... [T] he payoffs from this sophisticated scientific infrastructure development are yet to be realized. (p. 56, emphasis added) 
Drug therapy

[W] have yet to have fundamental advances in drug therapy. . . Newer drugs such as selective serotonin reuptake inhibitors (SSRIs) and atypical antipsychotics appear generally to be no more efficacious than earlier medications. (p. 56, emphasis added)

\section{Mental disorder conceptualization}

[O]ur understanding of the major mental disorders is still limited. . . History teaches us that it is easy to make claims of being on the threshold. A certain modesty is needed, as well as a willingness to be open to new conceptualizations, theories, methods, and approaches. The DSM is an important example. Developed as a descriptive convenience. ..DSM has been reified in ways that are not constructive. DSM is no more than a convenient instrument and should not be used as a standard to limit research on alternate approaches.... Given the many uncertainties that. . characterize treatment of mental disorders there is a concern with the present focus on biological aspects and the preference of managed care for medication treatments over psychotherapy, counseling or other modalities.

(pp. 56-57)

Given the tentativeness of what is "known" about mental disorderliness based on the current research, and the emphasis placed, even by mainstream psychiatric experts, on not disregarding alternate perspectives, explanations, and treatments, many of which are the considered strengths of social work, should we not then offer these alternatives for the critical consideration of our students?

\section{References}

Abbot, A. (1988). The system of professions. Chicago: University of Chicago.

American Psychiatric Association. (1980). Diagnostic and statistical manual of mental disorders (3rd ed.). Washington, DC: Author.

American Psychiatric Association. (1998). DSMIV sourcebook. Washington, DC: Author.

American Psychiatric Association. (2000). Diagnostic and statistical manual of mental disorders-IV, text revision (4th ed.). Washington, DC: Author.

America's Best Graduate Schools 2004. U.S. News and World Report. Retreived July, 2003 from http:/ / www.usnews.com/usnews / edu/ $\operatorname{grad} /$ rankings/hea/brief/socwrk_brief.php.

Andreasen, N. C., \& Black, D. W. (2001). Introductory textbook of psychiatry (3rd ed.). Washington, DC: American Psychiatric Publishing.

Antonuccio, D. (1995). Psychotherapy for depression-no stronger medicine. American Psychologist, 50, 450-452.

Antonuccio, D., Burns, D., Danton, W., \& O'Donahue, W. (2000). Rumble in Reno: The psychosocial perspective on depression. Psychiatric Times, 8(8). Retrieved January 12, 2003, from http://www.psychiatrictimes .com/p000824.html

Austrian, S. G. (2000). Mental disorder, medications, and clinical social work (2nd ed.). New York: Columbia University Press.

Bentley, K. J., \& Walsh, J. F. (2001). The social worker and psychotropic medication: Toward effective collaboration with mental health cli- 
ents, families, and providers (2nd ed.). Belmont, CA: Wadsworth/Thomson Learning.

Boyle, M. (2002). Schizophrenia: A scientific delusion? (2nd ed.). New York: Taylor \& Francis.

Breggin, P. R. (1991). Toxic psychiatry: Why therapy, empathy and love must replace the drugs, electroshock and biochemical theories of the "new psychiatry." New York: St. Martin's.

Breggin, P. R. (1997). Brain-disabling treatments in psychiatry: Drugs, electroshock, and the role of the FDA. New York: Springer.

Breggin, P. R. (1998). Talking back to Ritalin: What doctors aren't telling you about stimulants for children. Monroe, ME: Common Courage Press.

Breggin, P. R., \& Cohen, D. (1999). Your drug may be your problem: How and why to stop taking psychiatric medications. Reading, MA: Perseus Books.

Brubeck, M. (1999). Social work and the DSM. In F. Turner (Ed.), Adult psychopathology: A social work perspective (pp.121-135). New York: Free Press.

Cohen, D. (1988). Social work and psychotropic drug treatments. Social Service Review, $62,576-599$.

Cohen, D. (1989). Biological basis of schizophrenia-the evidence reconsidered. Social Work, 34, 255-257.

Cohen, D. (Ed.). (1990). Challenging the therapeutic state: Critical perspectives on psychiatry and the mental health system [Special issue]. Journal of Mind and Behavior, 11, 247-574.

Cohen, D. (1997). A critique of the use of neuroleptic drugs in psychiatry. In S. Fisher \& R.P. Greenberg (Eds.), From placebo to panacea: Putting psychotropic drugs to the test (pp. 173229). New York: Wiley.
Cohen, D. (2002). Research on the drug treatment of schizophrenia: A critical appraisal and implications for social work education. Journal of Social Work Education, 38, 217-239.

Cohen, D., \& Jacobs, D. (2000). A model consent form for psychiatric drug treatment. Journal of Humanistic Psychology, 20(1), 59-64.

Corson, P. W., Nopoulos, P., Miller, D. D., Arndt, S., \& Andreason, N. C. (1999). Changes in basal ganglia volume over 2 years in patients with schizophrenia: Typical versus atypical neuroleptics. American Journal of Psychiatry, 156, 1200-1204.

DeGrandpre, R. J. (1999). Ritalin nation: Rapid-fire culture and the transformation of human consciousness. New York: W.W. Norton

DiNitto, D. M. (2000). Social welfare: Politics and public policy (5th ed.). Boston: Allyn \& Bacon.

Drolen, C. S. (1993). The effect of educational setting on student opinions of mental illness. Community Mental Health Journal, 29, 223-234.

Duesberg, P. (1996). Inventing the AIDS virus. Washington, DC: Regnery.

Dziegielewski, S. F. (2001). Social work practice and psychopharmacology. New York: Springer.

Fancher, R. T. (1995). Cultures of healing: Correcting the image of American mental health care. New York: Freeman.

Fisher, S., \& Greenberg, R. P. (1989). The limits of biological treatments for psychological distress: Comparisons with psychotherapy and placebo. Hillsdale, NJ: Erlbaum.

Fisher, S., \& Greenberg, R. P. (1997). From placebo to panacea: Putting psychiatric drugs to the test. New York: Wiley.

Fox Piven, F., Acker, J., Hallock, M., \& Morgen, S. (2002). Work, welfare and politics: Confronting poverty in the wake of welfare reform. Eugene, OR: University of Oregon. 
Gambrill, E. (1994). Preface. In S. A. Kirk \& S. D. Einbinder (Eds.), Controversial issues in mental health (pp. ix-x). Boston: Allyn \& Bacon.

Gambrill, E. (1999). Evidence-based practice: An alternative to authority-based practice. Family in Society, 80, 341-350

Gelman, S. (1999). Medicating schizophrenia: A history. New Brunswick, NJ: Rutgers University Press.

Gilbert, N., \& Terrell. P. (2002). Dimensions of social welfare policy (5th ed.). Boston: Allyn \& Bacon.

Glenmullen, J. (2000). Prozac backlash: Overcoming the dangers of Prozac, Zolof, Paxil and other antidepressants with safe, effective alternatives. New York: Simon and Schuster.

Gomory, T. (1998). Coercion justified? Evaluating the training in community living model: A conceptual and empirical critique. Dissertation Abstracts International, 59. (UMI No. 9902082).

Gomory, T. (1999). Programs of assertive community treatment (PACT): A critical review. Ethical Human Sciences and Services, 1, 147-163.

Gomory, T. (2001). A fallibilistic response to Thyer's theory of theory-free empirical research in social work practice. Journal of Social Work Education, 37, 26-50.

Gomory, T. (2002). The origins of coercion in assertive community treatment: A review of early publications from the special treatment unit of Mendota state hospital. Ethical Human Sciences and Services, 4(1), 3-16.

Goode, E. (2002, January 14). Study finds jump in children taking psychiatric drugs. New York Times, p. A18.

Grob, G.N.(1994).Themadamong us: A historyofthecare of America's mentally ill. New York: Free Press.

Hales, D. R., \& Hales, R. E. (1995). Caring for the mind: The comprehensive guide to mental health. New York: Bantam.
Healy, D. (1997). The antidepressant era. Cambridge, MA: Harvard University Press.

Healy, D. (2000). Emergence of antidepressant induced suicidality. Primary Care Psychiatry, 6(1), 23-28.

Healy, D. (2001). The SSRI suicides. In C. Newnes, G. Holmes, \& C. Dunn (Eds.), This is madness too (pp. 59-69). Herefordshire, UK: PCCS Books.

Healy, D. (2002). The creation of psychopharmacology. Cambridge, MA: Harvard University.

Hyman, S. E. (1998). Schizophrenia: Understanding it, treating it, living with it. Paper presented at the National Institute of Mental Health and the Library of Congress Project on the Decade of the Brain. Abstract retrieved January 16, 2002, from http:/www.nimh.nih.gov/ events/locschiz.cfm

Jacobs, D. H. (1995). Psychiatric drugging: Forty years of pseudo-science, self interest, and indifference to harm. Journal of Mind and Behavior, 16, 421-470.

Jacobs, D. H. (1999). A close and critical examination of how psychopharmacotherapy research is conducted. Journal of Mind and Behavior, 20, 311-349.

Jacobs, D. H., \& Cohen, D. (in press). Hidden in plain sight: DSM IV's rejection of the categorical approach to diagnosis. Review of Existential Psychology and Psychiatry.

Johnson, H. C. (1999a). Psyche, synapse, and substance: The role of neurobiology in emotions, behavior, thinking, and addiction for non-scientists. Greenfield, MA: Deerfield Valley.

Johnson, H. C. (1999b). The biological basis of psychopathology. In F. Turner (Ed.), Adult psychopathology: A social work perspective (pp. 54-99). New York: Free Press. 
Johnson, H. C. (2002). Emerging knowledge and future trends in mental health: Implications for social work. In K. J. Bentley (Ed.), Social work practice in mental health: Contemporary roles, tasks and techniques (pp. 361-391). Pacific Grove, CA: Brooks/Cole.

Johnstone, L. (2000). Users and abusers of psychiatry: A critical look at psychiatric practice (2nd ed.). Philadelphia, PA: Routledge.

Joseph, J. (2000). Inaccuracy and bias in textbooks reporting psychiatric research: The case of the schizophrenia adoption studies. Politics and the Life Sciences, 19, 89-99.

Kaplan, H. I., \& Saddock, B. J. (1998). Synopsis of psychiatry (8th ed.). Baltimore, MD: Williams and Wilkins.

Karger, H. J., \& Stoesz, D. (2002). American social welfare policy: A pluralist approach (4th ed.). Boston: Allyn \& Bacon.

Kirk, S. A., \& Hsieh, D. K. (in press). Diagnostic consistency in assessing conduct disorder: An experiment of the effect of social context. American Journal of Orthopsychiatry.

Kirk, S. A., \& Kutchins, H. (1992). The selling of DSM: The rhetoric of science in psychiatry. New York: Aldine de Gruyter.

Kirk, S. A., \& Kutchins, H. (1994). The myth of the reliability of DSM. Journal of Mind and Behavior, 15, 1-2.

Kirk, S. A., Siporin, M., \& Kutchins, H. (1989). The prognosis for social work diagnosis. Social Casework: The Journal of Contemporary Social Work, 70, 295-307.

Kirsch, I., \& Sapirstein, G. (1998). Listening to Prozac but hearing placebo: A meta-analysis of antidepressant medication. Prevention $\mathcal{E}$ Treatment, 1, Article 0002a. Retrieved January 12, 2003, from http:/ /journals.apa.org/ prevention/volume1/pre0010002a.html
Kirsch, I., Moore, T.J., Scoboria, A., \& Nicholls, S. S. (2002). The emperor's new drugs: An analysis of antidepressant medication data submitted to the U.S. Food and Drug Administration. Prevention and Treatment, 5. Retrieved January 12, 2003, from http:// journals.apa.org/prevention/volume5/ pre0050023a.html

Knutson, B., Wolkowitz, O. M., Cole, S. W., Chan, T. Moore, E. A., et al. (1998). Selective alteration of personality and social behavior by serotonergic intervention. American Journal of Psychiatry, 155, 373-379.

Kutchins, H., \& Kirk, S. (1988). The business of diagnosis: DSM-III and clinical social work. Social Work, 33, 215-220

Kutchins, H., \& Kirk, S. A. (1995). Should DSM be the basis for teaching social work practice in mental health? No! Journal of Social Work Education, 31, 159-165.

Kutchins, H., \& Kirk, S. A. (1997). Making us crazy: DSM: The psychiatric bible and the creation of mental disorders. New York: FreePress.

Leiby, J. (1978). A history of social welfare and social work in the United States. New York: Columbia University Press.

Leo, J., \& Cohen, D. (2003). Broken brains and flawed studies? A critical review of ADHD neuroimaging research. The Journal of Mind and Behavior, 24(1), 29-56.

Levy, S. (1981). Labeling: The social worker's responsibility. Social Casework, 62, 332-342.

Lewis, S. J. (2003). Do one shot preventive interventions for PTSD work? A systematic research synthesis of psychological debriefings. $A g$ gression and Violent Behavior, 8, 329-343

Lubove, R. (1983). The professional altruist: The emergence of social work as a career, 1880-1930. New York: Atheneum. 
Margolin, L. (1997). Under the cover of kindness: The invention of social work. Charlottesville, VA: University Press of Virginia.

Maxmen, J. S., \& Ward, N. G. (1995). Essential psychopathology and its treatment (2nd ed.). New York: Norton.

McNeece, C. A., \& DiNitto, D. M. (1998). Chemical dependency: A systems approach. Boston: Allyn \& Bacon.

Mechanic, D. (2000). Mental health policy at the millennium: Challenges and opportunities. In R. W. Manderscheid \& M. J. Henderson (Eds.), Mental health, United States, 2000 (pp. 53-63). Rockville, MD: United States Department of Health and Human Services, Substance Abuse and Mental Health Services Administration.

Miller, J. (2002). Social workers as diagnosticians. In K. J. Bentley (Ed.), Social work practice in mental health: Contemporary roles, tasks and techniques (pp. 43-72). Pacific Grove, CA: Brooks/Cole.

National Alliance for the Mentally Ill. (n.d.). Understanding major depression: What you need to know about this medical illness. Retrieved January 11, 2003, from http:/ /www.nami.org/helpline/ UnderstandingMajorDepression.pdf

National Institutes of Health. (1998). Diagnosis and treatment of Attention Deficit Hyperactivity Disorder. NIH Consensus Statement Online, 16(2), 1-37. Retrieved January 11, 2003, from http:/ / odp.od.nih.gov/consensus / cons/110/110_statement.htm.

National Institute of Mental Health. (1999). Welcome page. Retrieved January 23, 2003, from http: / / www.nimh.nih.gov/about / index.cfm

National Institute of Mental Health. (2000). Schizophrenia research at the National Institute of
Mental Health (NIMH Publication No. 004500). Bethesda, MD: Author.

Nickerson, R. S. (1998). Confirmation bias: A ubiquitous phenomenon in many guises. Review of General Psychology, 2(2), 175-220.

Nolen-Hoeksema, S. (1998). Abnormal psychology. Boston: McGraw-Hill.

Peterson, M. (2002, August 21). Judge orders drug company to alter ads. New York Times, p. C6.

Raffoul, P. R., \& Holmes, K. A. (1986). DSM-III content in social work curricula: Results of a national survey. Journal of Social Work Education, 22(1), 24-31.

Reamer, F. G. (1993). The philosophical foundations of social work. New York: Columbia University Press.

Rosenhan, D. L. (1973). On being sane in insane places. Science, 179, 250-258.

Ross, C. A., \& Pam, A. (1995). Pseudoscience in biological psychiatry: Blaming the body. New York: Wiley.

Rothman, D. J. (1990). The discovery of the asylum: Social order and disorder in the new republic. Boston: Little Brown.

Royse, D. D. (1999). Research methods in social work (3rd ed.). Chicago: Nelson-Hall

Rubin, A., Cardenas, J., Warren, K., Pike, C., \& Wambach, K. (1998). Outdated practitioner views about family culpability and severe mental disorders. Social Work, 43, 412-422.

Scheff, T. J. (1999). Being mentally ill: A sociological theory (3rd ed.). New York: Aldine de Gruyter.

Schoenfeld, C. G. (1976). An analysis of the views of Thomas S. Szasz. Journal of Psychiatry $\mathcal{E}$ Law, 4, 245-263.

Scull, A. T. (1981). Madhouses, mad-doctors, and madmen: The social history of psychiatry in the 
Victorian era. Philadelphia: University of Pennsylvania Press.

Shera, W., \& Delva-Tauiliili, J. (1996). Changing MSW students' attitudes towards the severely mentally ill. Community Mental Health Journal, 32(2), 159-169.

Sherraden, M. W. (1991). Assets and the poor: A new American welfare policy. Armonk, NY: M. E. Sharpe.

Szasz, T. (1987). Insanity: The idea and its consequences. New York: Wiley.

Szasz, T. (2001). Pharmacracy: Medicine and politics in America. Westport, CT: Praeger.

Taylor, R. (1987). Biological basis of schizophrenia. Social Work, 32, 115-121.

Thyer, B. A., \& Wodarski, J. S. (Eds.). (1998). Handbook of empirical social work practice. New York: Wiley.

Trattner, W. (1979). From poor law to welfare state: A history of social welfare in America (2nd ed.). New York: Free Press.

Turner, F. J. (Ed.). (1999). Adult psychopathology: A social work perspective (2nd ed.). New York: Free Press.

Tyson, K. (1991). The understanding and treatment of childhood hyperactivity: Old problems and new approaches. Smith College Studies in Social Work, 61(2), 133-166.

U.S. Department of Health and Human Services. (1999). Mental health: A report of the surgeon general. Rockville, MD: U.S. Department of Health and Human Services, Substance Abuse and Mental Health Services Administration.

Valenstein, E. S. (1998). Blaming the brain: The truth about drugs and mental health. New York: Free Press.

Vatz, R. E., \& Weinberg, L. S. (1983). Thomas Szasz: Primary values and major contentions. Buffalo, NY: Prometheus Books.
Vatz, R. E., \& Weinberg, L. S. (1994). The rhetorical paradigm in psychiatric history: Thomas Szasz and the myth of mental illness. In M. S. Micale \& R. Porter (Eds.), Discovering the history of psychiatry (pp.311-330). New York: Oxford University.

Wakefield, J. C. (1992a). Disorder as harmful dysfunction-a conceptual critique of DSMIII-R's definition of mental disorder. Psychological Review, 99, 232-247.

Wakefield, J. C. (1992b). The concept of mental disorder. American Psychologist, 47, 373-388.

West, J., Kohout, J., Pion, G. M., Wicherski, M. M., Vandivort, R. E., Palmiter, M. L., et al. (2000). Mental health practitioners and trainees. In R. W. Manderscheid \& M. J. Henderson (Eds.), Mental health, United States, 2000 (pp. 279-315). Rockville, MD: United States Department of Health and Human Services, Substance Abuse and Mental Health Services Administration.

White, R. D. (2002, October 11). California: Order blocking Paxil ads is lifted. Los Angeles Times, C2.

Widiger, T. A., \& Sankis, L. M. (2000). Adult psychopathology: Issues and controversies. Annual Review of Psychology, 51, 377-404.

Williams, J. B., \& Spitzer, R. L. (1995). Should the $D S M$ be the basis for teaching social work practice in mental health? Yes! Journal of Social Work Education, 31, 148-153.

Wylie, M. S. (1995). Diagnosing for dollars? Family Therapy Networker, 19(3), 23-33, 65-69.

Zametkin, A. J., Nordahl, T. E., Gross, M., King, A. C., Semple, W. E., Rumsey, J., et al. (1990). Cerebral glucose metabolism in adults with hyperactivity of childhood onset. New England Journal of Medicine, 323, 1361-1366. 
Zametkin, A. J., Liebenauer, L. L., Fitzgerald, G. A., King, A. C., Minkunas, D. V., Herscovitch., P., et al. (1993). Brain metabolism in teenagers with attention-deficit hyperactivity disorder. Archives of General Psychiatry, 50, 333-340.

Zide, M. R., \& Gray, S. W. (2001). Psychopathology: A competency-based assessment model for social workers. Belmont, CA: Wadsworth/Thomson Learning.

Zimbardo, P. C. (1999). Discontinuity theory: Cognitive and social searches for rationality and normality may lead to madness. In M. P. Zanna (Ed.), Advances in Experimental Social Psychology, 31, pp. 345-486. San Diego, CA: Academic Press.

Accepted: 07/03.

Jeffrey R. Lacasse is a doctoral student and Tomi Gomory is assistant professor, School of Social Work, Florida State University.

Address correspondence to Tomi Gomory, School of Social Work, Florida State University, Office-UCC 2410, Tallahassee, FL 32306-2570; email: tgomory@mailer.fsu.edu. 